\title{
Parametric Design of Cutting Head of Roadheader and Toothholder Secondary Development Based on UG
}

\author{
Junhong Ji, Jichao Yang \\ (College of Mechanical Engineering; Liaoning Technical University; Fuxin 123000;China) \\ yangjichao1580@163.com
}

Keywords: Road header; UG; Second development; Cutting pick; Tooth holder; Parametric design

\begin{abstract}
Based on the analysis of transverse road header cutting head and toothholder, using $\mathrm{VC}++$ and UG provide UG/OPEN API, Manuscript and UI Styler joint second development, obtained parametric design program of Cutting Head of Road header and toothholder. Use the program, intuitively understand to different sizes of Road header and tooth holder interference, and to determine reasonable Road header and tooth holder place, proper design determing transverse roadheader cutting head.
\end{abstract}

\section{Introduction}

Cutting pick and tooth holder is main parts of the roadheader cutting head. And design the cutting pick and tooth holder generally according to the load of cutting head to choose the main size parameters. However, in order to obtain the ideal cutting performance, it generally adopt the "top-down" to design the cutting head — first, to do the design to arrangement cutting pick, then assemble cutting pick in accordance with the cutting pick arrangement[1,2]. Because the particularity of the cutting head design making choosing unreasonable size of the cutting pick and tooth holder may cause interference and can not realize the original cutting pick arrangement design. If it can do parametric design in the virtual assembly good cutting head of cutting pick and tooth holder and in meet the strength requirements of the situation, reasonably change cutting pick and tooth holder size parameters and avoid interference, try to preserve the original cutting pick alignment design. So it can improve the cutting head design efficiency.

\section{The Parametric Design of the Cutting Pick and Tooth Holder}

Cutting Pick and Tooth Holder. The coal industry standard of the People's Republic of China [3,4] has formulated the related standard respectively on the cutting pick and tooth holder. The two standards are about the classification, type and basic size and requirements of the cutting pick and tooth holder. While making the size parameter standard, it only formulate standard on a few key size. And there are still a lot of sizes no definition, for these sizes we design availably.

Cutting pick can be divided into flat pick and pick-like bit two kinds according to the geometric shape. For the two types of cutting pick, pick-like bit is most widely used, since it has self-sharpening and shock resistance, and it's suitable for cutting hard rock characteristics etc. At present the new roadheader all adopt pick-like bit. So this procedure choose pick-like bit and tooth holder as parameterized objects.

The cutting pick is the parts broken coal rock directly. It is divided into carbide head and tooth body two parts, and tooth body is divided into tooth head and tooth handle two parts. Tooth holder is the parts to connect cutting pick and cutting head body. On the one hand, it fixes cutting pick, on the other hand it is welded on the cutting head body.

Parametric Design. Using provides the UG/OPEN API, Menuscript and UI Styler provided by $\mathrm{VC}++$ and UG joints for secondary development. And its several necessary working:

(1) Environment Settings. Establish directory E:/ugapi. Add the environment variable UGII_USER_DIR, and its value is E:/ugapi. Then establish new directory startup and application under directory E: / ugapi. 
(2) Set menu. Compile menu script file *.men by using notepad, and save in the directory startup.

(3) Set interface. Under the UGGeteway state, choose application and choose user interface editor, then enter into UIStyler. Set interface, and save it to directory application, generate three files *.DLG, *.H and *.C.

(4) VC++ Settings. (1)New construction. Start Vistual C++ and create a new project name, and the name is to jiechichizuo. Now choose Win32Dynamic-Link Library and An empty DLL Project (or UG/OPEN APP Wizard, this kind of means has established UG application framework, including inlet function). (2)The project settings. Enter the $\mathrm{C} / \mathrm{C}++$, and set Category to Code Generation then set Use run-time library to Multithread DLL. Enter into the Project-Setting-Link pages and fill the final compiled connection DLL file name and path E:/ugapi/startup/Jiechichizuo in the text box Output file name. Add the library name libyfun.lib, libugopenint.lib into the textbox Object/Library modules. Enter the Tools-Options-Directions page, set Show directories for to include files and add the catalog D:|PROGRAMFILES $\backslash U G \backslash U G$ OPEN of UF library files in Directories. Enter Tools-Options-Directions page again, set Show directories for to include files and add the catalog D:|PROGRAMFILES $\backslash U G \backslash U G$ OPEN of UF library files in Directories [6].

(5) Create new ".cpp" and ".h" file. (1)Add *.C and *.H under the directory "application " into the project. (2)Regard the function ufsta() as entry and remove its \#ifdef and \#endif. (3)Write the main program. Add its program code into the dialog box callback function templates. Here it explains the main function UF_MB_add_styler_actions(): the function UF_MB_add_styler_actions() is used to associate the response behavior of UI Styler dialog interface and menu script file. The dialog box file must generate by UI Styler and should save in the directory application. (4)Compile and link. Produce the executable file jiechichizuo.dll, and save automatically to the directory startup.

Before develop the program, it need set to parameters for the cutting pick and tooth holder model which is called by the program. It sets the parameters of the cutting pick and tooth holder respectively under UG environment and link size and parameters by using relationships, so it can change parameter can change the corresponding size and parameters. So the program uses the mean.

Program flow chart is shown in fig. 1.

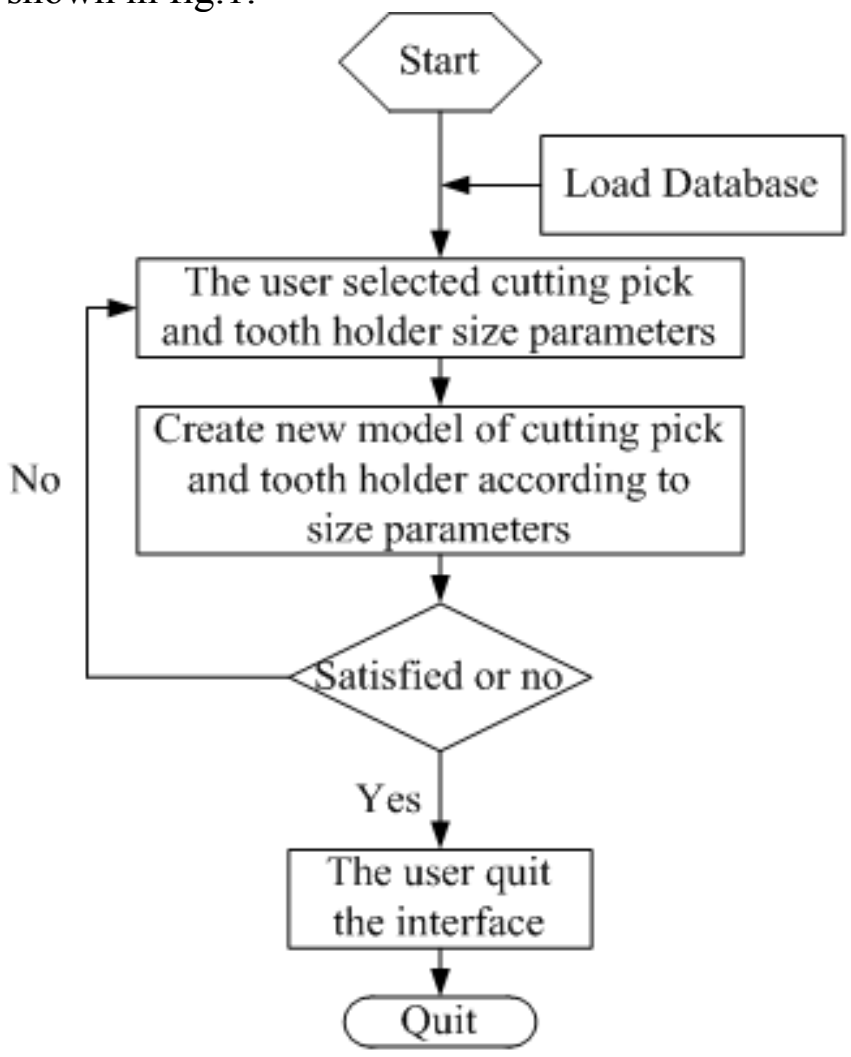

Fig.1 Program flow chart 
The Parametric Design Interface of Cutting Pick and Tooth Holder. Because the pick-like bit is divided into A and B types. The program develops two interfaces in view of the two types. Because the difference exists in a few design parameters of the two types, the section describes the A type as shown in fig.2.

In the interface left, it gives graphics of cutting pick and tooth holder and its letters of the. In these, the part is the design standard size and the other part is not which the user can design itself. In order to avoid trival, some unimportant and not specified sizes adopt UG parameters drive to adjust the size automatically.

The list on the right of cutting pick and tooth holder picture records data in the standard. All these data is stored in the database. When open the interface the data displays in the list from database. Because the interface space is limited, it only shows the tooth shank diameter D and the cutting pick length $\mathrm{L}$, the user choose different size cutting pick according to the two main value. When click any item of the list box, all data of cutting pick and tooth holder display in edit box of "standard" panel. After click "Regeneration Model" button, it will give the model of cutting pick and tooth holder according to the size in the edit box. When click "Current Size", it can obtain the size of cutting pick and tooth holder and display in the edit box.

This program makes full use of the size in the standard, but does not only use the standard. After the size display in edit box, the user can adjust and change accordingly. So the cooperation of using standard and users can greatly improve the efficiency of the parametric design.

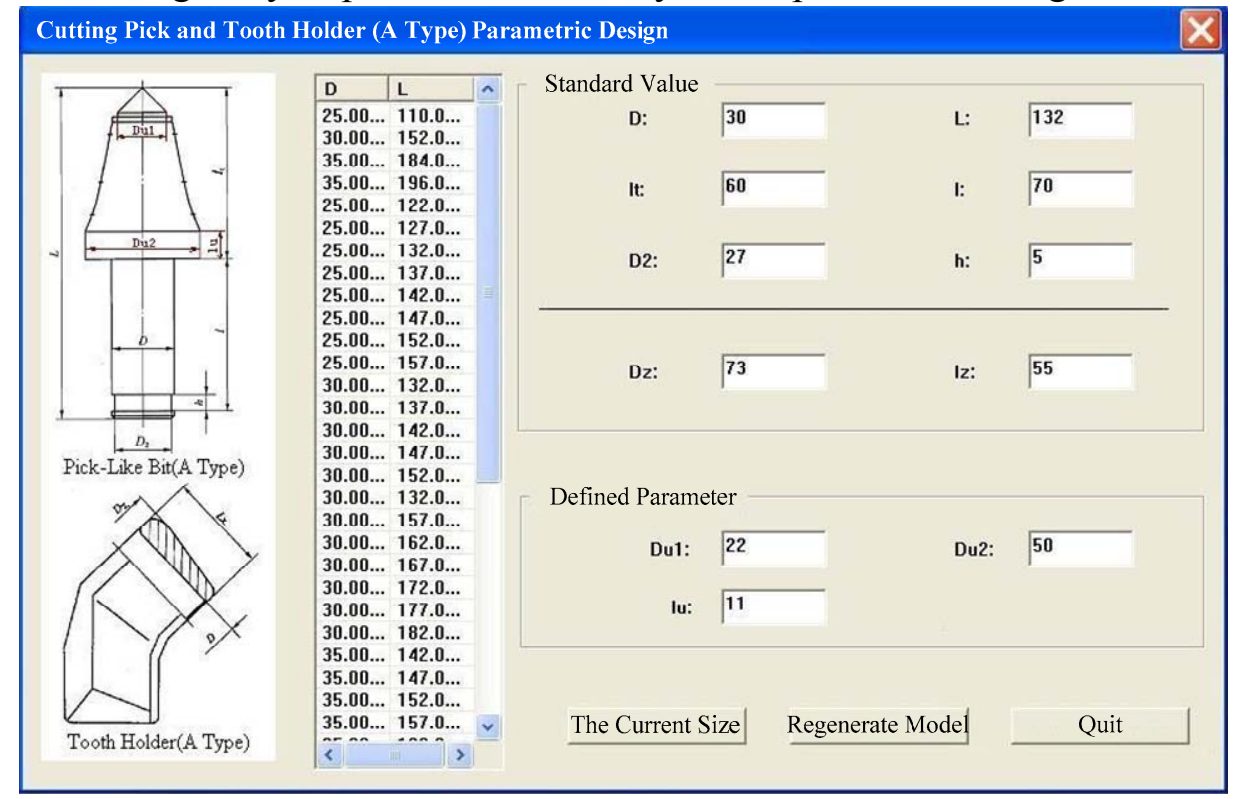

Fig.2 A type cutting pick and tooth holder design interface

\section{Design example}

In this section it creates two kinds of assembly body in different size by using the same kind of cutting pick arrangement. The size of two different cutting pick and tooth holder is shown table 1 and the mean of letters is shown in fig.2. The assembly drawings of different cutting pick and tooth holder in different size. Fig.2(a) is the assembly drawing of No.1, there is no mutual interference through the assembly drawing global interference inspection, but it exists in fig.2(b). And the red part in fig.2(b) is the interference of cutting pick and tooth holder. From the example it can see that the size of cutting pick and tooth holder influence the interference in the same kind of cutting pick arrangement.

Table1 The parameters of cutting pick and tooth holder

\begin{tabular}{cccccccccccc}
\hline No. & $\begin{array}{c}\mathrm{D} \\
/ \mathrm{mm}\end{array}$ & $\begin{array}{c}\mathrm{L} \\
/ \mathrm{mm}\end{array}$ & $\begin{array}{c}\mathrm{lt} \\
/ \mathrm{mm}\end{array}$ & $\begin{array}{c}\mathrm{l} \\
/ \mathrm{mm}\end{array}$ & $\begin{array}{c}\mathrm{D} 2 \\
/ \mathrm{mm}\end{array}$ & $\begin{array}{c}\mathrm{h} \\
/ \mathrm{mm}\end{array}$ & $\begin{array}{c}\mathrm{Dz} \\
/ \mathrm{mm}\end{array}$ & $\begin{array}{c}\mathrm{lz} \\
/ \mathrm{mm}\end{array}$ & $\begin{array}{c}\mathrm{Du} 1 \\
/ \mathrm{mm}\end{array}$ & $\begin{array}{c}\mathrm{Du} 2 \\
/ \mathrm{mm}\end{array}$ & $\begin{array}{c}1 \mathrm{u} \\
/ \mathrm{mm}\end{array}$ \\
\hline 1 & 30 & 132 & 60 & 70 & 27 & 5 & 73 & 55 & 22 & 50 & 11 \\
2 & 35 & 152 & 80 & 70 & 32 & 5 & 73 & 65 & 22 & 60 & 15 \\
\hline
\end{tabular}




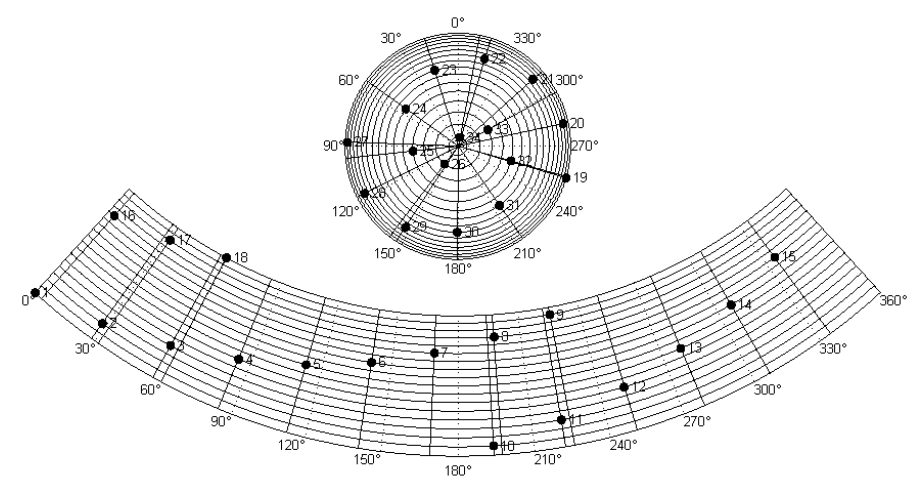

Fig.3 The chart of cutting pick arrangement

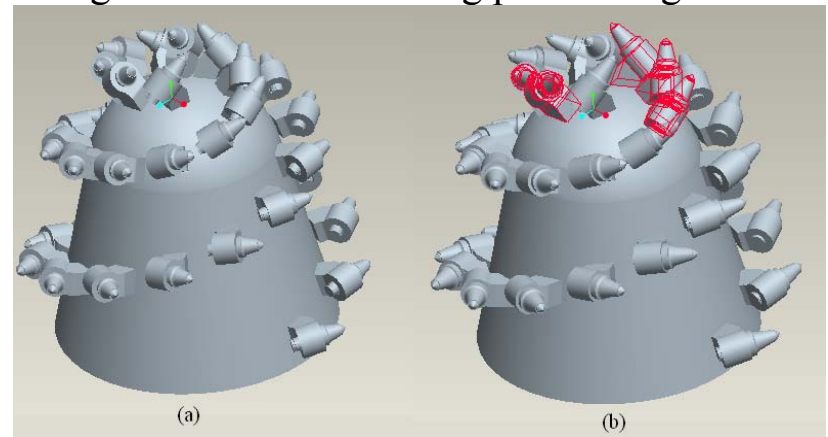

Fig.4 The chart of cutting pick arrangement

\section{Summary}

1. Doing cutting pick and tooth holder parametric design is good to observe whether there is interference between cutting pick and tooth holder under the situation of given cutting pick arrangement and to quickly get cutting pick and tooth holder fitting the design requirements.

2. In the process of parametric interface design, it does not only considers the existing standard size cutting pick and tooth holder, but also keep the user's rights to change the size, highlight the key size and do parametric driving on some minor sizes.

3. Through using the program, the user can real-time generate different assembly body of cutting head, and get the right size model of the cutting pick and tooth holder so to improve the design efficiency.

\section{References}

[1] Xiaohuo Li: The design and research of roadheader cutting head[M]. Beijing: China's Overseas Chinese Press, 1997

[2] Xiaohuo Li: The key technology research of roadheader cutting[M]. Beijing: China Machine Press, 2008

[3] The coal industry coal mine special equipment standardization technical committee. MT/T246-2006: Mining machinery cutting pick[S]. Beijing: China Coal Industry Publishing House, 2006

[4] The coal industry coal mine special equipment standardization technical committee. MT/T247-2006: Mining machinery tooth holder[S]. Beijing: China Coal Industry Publishing House, 2006

[5] Yujian Wang: Visual C++ object-oriented editing tutorial[M].Beijing: Tsinghua University Press, 2003.9, 102-104

[6] Ye Zhang, Xue Hong, Zebang Zhang: Unigraphics XN parametric design example tutorial[M]. Beijing: Tsinghua University Press, 2003.8:435-348 